\title{
High prevalence of urinary
} schistosomiasis in a desert population: results from an exploratory study around the Ounianga lakes in Chad

\author{
Wendelin Moser ${ }^{1,2}$, Annour Adoum Bati ${ }^{3}$, Rebekka Ott ${ }^{1,2}$, Moussa Abderamane ${ }^{4}$, Ruth Clements ${ }^{5}$,
} Rahel Wampfler ${ }^{1,2}$, Sven Poppert ${ }^{1,2}$, Peter Steinmann ${ }^{1,2}$, Fiona Allan ${ }^{5}$ and Helena Greter ${ }^{1,2^{*}}$ (D)

\begin{abstract}
Background: Researching a water-borne disease in the middle of the Sahara desert might not seem the most relevant concern. However, nomadic Sahelian pastoralists health concerns regarding their livestock and anecdotal reports about trematode infections of Fasciola spp. and Schistosoma spp. in desert-raised animals justified an exploratory study focusing on the lakes of Ounianga in Northern Chad. The aim was to test whether trematode parasites such as Schistosoma spp. occur in human populations living around the Sahara desert lakes of Ounianga Kebir and Ounianga Serir in northern Chad.
\end{abstract}

Methods: The study was carried out in January 2019 and comprised of three components. First, a cross sectional survey based on a random sample drawn from the population to detect infections with S. haematobium and S. mansoni; second, focus group discussions exploring disease priorities, access to health and health seeking behaviour; and third, surveying water contact sites for intermediate host snails. Samples of trematode parasites and snails were confirmed on species level by molecular genetic methods. For parasitological and malacological surveys descriptive statistics were performed. Qualitative data analysis included the full review of all transcripts, followed by a descriptive and explorative thematic analysis.

Results: Among 258 participants, the overall S. haematobium prevalence using urine filtration was 39.2\% [95\% confidence interval (CI): 33.5-45.1\%], with 51.5\% of the infected suffering from heavy infection. The intermediate host snail of S. haematobium (Bulinus truncatus) occurred at water contact sites near both study villages, revealing the potential for local transmission. Although a positive S. mansoni point-of-care circulating cathodic antigen (POC-CCA) test result was obtained from $8.6 \%$ (95\% Cl 5.7-12.8\%) of the samples, no intermediate host snails of S. mansoni were found, and the relevance of $S$. mansoni remains uncertain. Qualitative findings underline the importance of morbidity caused by urinary schistosomiasis, and the lack of access to diagnostics and treatment as a major health concern.

Conclusions: This research revealed a high prevalence of urinary schistosomiasis in the population living around the lakes of Ounianga in the Sahara, a United Nations Educational, Scientific and Cultural Organization (UNESCO) world heritage site in Chad. Despite the high public health importance of the associated morbidity expressed by the

${ }^{*}$ Correspondence: helena.greter@swisstph.ch

1 Swiss Tropical and Public Health Institute, Basel, Switzerland

Full list of author information is available at the end of the article permits use, sharing, adaptation, distribution and reproduction in any medium or format, as long as you give appropriate credit to the original author(s) and the source, provide a link to the Creative Commons licence, and indicate if changes were made. The images or other third party material in this article are included in the article's Creative Commons licence, unless indicated otherwise in a credit line to the material. If material is not included in the article's Creative Commons licence and your intended use is not permitted by statutory regulation or exceeds the permitted use, you will need to obtain permission directly from the copyright holder. To view a copy of this licence, visit http://creativecommons.org/licenses/by/4.0/. The Creative Commons Public Domain Dedication waiver (http://creativeco mmons.org/publicdomain/zero/1.0/) applies to the data made available in this article, unless otherwise stated in a credit line to the data. 
population, there is no access to diagnostics and treatment. Further work is needed to develop and test a contextadapted intervention.

Keywords: Bulinus truncatus, Chad, Malacology, Ounianga, POC-CCA, Prevalence, Sahara, Schistosoma bovis, Schistosoma haematobium, Schistosomiasis

\section{Graphical Abstract}

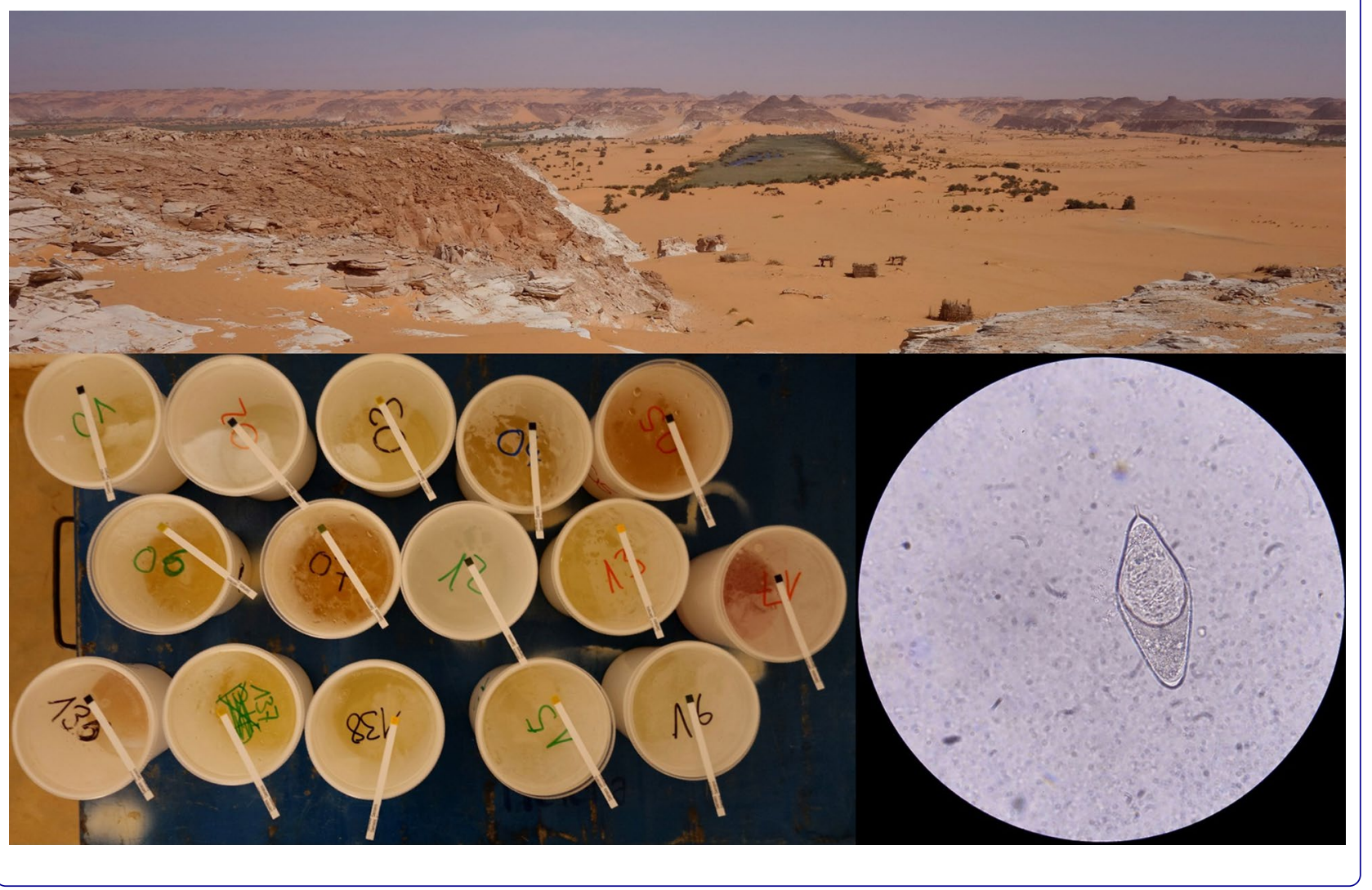

\section{Background}

Schistosome infections are listed among the 20 neglected tropical diseases (NTDs) targeted by the World Health Organisation (WHO) for elimination by 2030 [1]. In endemic regions, populations affected by schistosomiasis are often those living in poverty and/or in settings with restricted access to clean water for their sanitation and hygiene needs [2]. Worldwide, an estimated 230 million people harbour an infection with Schistosoma spp [3]. Occupational and recreational activities in close contact with freshwater, e.g., fishing, doing laundry and bathing present the main risk of infections. Highest prevalences are commonly observed among school-aged children as they enjoy playing in stagnant water sites. Undetected, and therewith untreated, urinary or intestinal schistosomiasis leads to chronic infections and serious morbidities including a wide range of different pathologies, e.g. anaemia, stunted growth, impaired cognition and organ damages, that negatively affect economic activities and therewith maintain poverty $[4,5]$. A safe and effective drug, namely praziquantel, is currently used for mass drug administration programs in endemic settings as well as for treatment of individual acute infections. However, its wide use in mass drug administration programs since 2006 bears the risk of selecting for resistance in the parasite population, a topic that raises concerns when therapeutic failure is observed and that is closely monitored [6].

The majority of schistosomiasis cases occur in subSaharan Africa, and the disease is also reported from countries throughout the Sahel, including Mauretania, Mali, Niger, Chad and Sudan [7-11]. Infections in the Sahel ecoregion are predominantly due to Schistosoma haematobium which has the ability to maintain its life cycle in a semi-arid environment [12]. Yet, there are old reports on schistosomiasis occurrence from within the Sahara desert $[7,13]$. The occurrence of Schistosoma spp. in the hot and hyper-arid desert may seem 
surprising but endemicity in at least two desert-specific ecosystems has been described so far. These are (a) oases where schistosome transmission is linked to man-made irrigation systems [14, 15], and (b) areas with reclaimed land for agriculture, made cultivable by artificial irrigation from deep wells [16].

Anecdotal reports from nomadic Sahelian pastoralists on Fasciola spp., another digenean trematode species, in livestock raised in the Chadian Sahara and recent reports about modern and early Holocene finding of intermediate host snails pointed towards the occurrence and potential ongoing transmission of schistosomiasis at the desert lakes of Ounianga, Chad [17]. Triggered by these information, an exploratory study was conceptualized with the aim to investigate whether trematode parasites such as Schistosoma spp. occur in two settlements at the lakes of Ounianga, Ennedi Ouest province, in Northern Chad. The study was covering three aspects, namely parasitology, malacology and the population's health priorities, their access to health care and treatment.

\section{Methods}

\section{Study site and study population}

The study was carried out in January 2019 around the lakes of Ounianga and in the two settlements of Ounianga Kebir and Ounianga Serir, Ennedi Ouest province in Northern Chad (Fig. 1). The lakes lie around $40 \mathrm{~km}$ apart from each other within the hyper-arid Sahara desert with high daytime temperatures and less than $5 \mathrm{~mm}$ of rainfall per year. The lakes are fed by an underground aquifer, thereby maintaining the fresh water in some of the lakes despite the enormously high evaporation rates. Therewith, the lakes of Ounianga represent a unique hydrological system [18].

The official population estimates according to the latest national population census for Ounianga Kebir stand at around 9000 people and for Ounianga Serir at about 1000 people [19]. The majority of these people belong to one of the three predominant ethnolinguistic groups of the Tedega, Dazaga Toubou and the Zaghawa. Their main occupational activities include pastoralism, natron mining and trade. In both communities, the primary schools are operational, yet not the secondary schools.

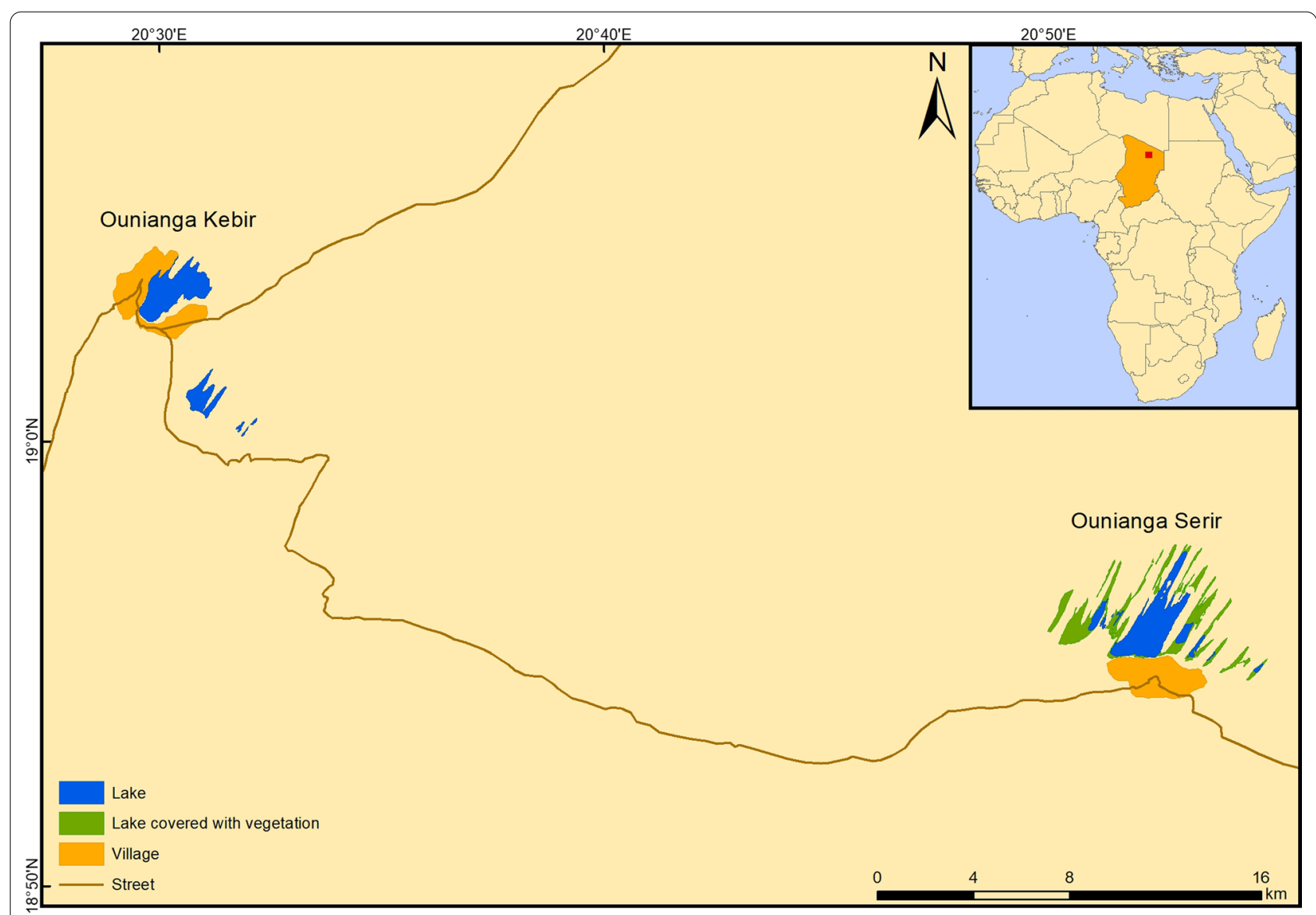

Fig. 1 A map showing the lakes and the settlements of Ounianga Kebir and Ounianga Serir in Northern Chad 
The only functional health centre of the Ounianga district is located in Ounianga Kebir and its catchment population is estimated to include 30,000 people. Ounianga Serir has no functional health centre; the population has set up a health post to provide basic health services to the community members.

\section{Parasitological survey}

The resident population of Ounianga Kebir and Ounianga Serir, older than 5 years of age, were eligible for participation. The sample size was calculated using Epi Info 7.1.3.3 (Centre for Disease Control (CDC), Atlanta, GA 30333, USA). Parameters used were "population survey" with two-sided confidence intervals of $95 \%$, an expected frequency of $50 \%$ and a population size of 10,000 , resulting in a sample size of 370 . Proportional to the total population estimates, the targeted sample size repartition was 330 people in Ounianga Kebir and 40 people in Ounianga Serir. At household level and at the primary schools, individuals were randomly selected by applying the spatial sampling method from the Expanded Programme on Immunization (EPI) of the WHO as previously published [20]. After obtaining oral consent from each selected individual, or in case of children from their caretakers, they were asked to produce a urine sample around noon, when S. haematobium egg excretion is known to peak [21]. A mobile field laboratory was set up at the health centre, and health post, respectively. The urine samples were analysed for haematuria by reagent strip testing (Hemastix; Siemens Healthcare Diagnostics $\mathrm{GmbH}$; Eschborn, Germany) and classified as negative, light and severe haematuria as outlined by the testing handbook. Subsequently, $10 \mathrm{ml}$ samples were subjected to urine filtration using a syringe and pressed through a 13-mm diameter filter holder containing a $20-\mu \mathrm{m}$ wiremesh filter (Sefar AG; Heiden, Switzerland), followed by microscopic screening of the filter content for the presence of S. haematobium eggs. The infection intensity was determined according to the 3 categories defined by the WHO as no infection (0 egg/10 ml urine), mild infection (1-49 eggs/10 ml urine) and heavy infection (50 or more eggs $/ 10 \mathrm{ml}$ urine) [22]. A point-of-care circulating cathodic antigen (POC-CCA) urine cassette test (Rapid Medical Diagnostics; Pretoria, South Africa) was performed to screen for $S$. mansoni infections. The POCCCA test applies a lateral flow principle and allows to detect adult Schistosoma worm CCA in the hosts' urine by adding a colloid carbon conjugate of a monoclonal antibody to the sample, and has been validated before for its performance under extreme environmental conditions as those occurring in the Sahara [23, 24].

\section{Qualitative survey}

In both communities, one focus group discussion (FGDs) with men and one with women were organized. Additionally, one FGD was organized with the staff of the health centre in Ounianga Kebir. In Ounianga Serir, an in-depth interview (IDI) was carried out with the person responsible for the health post. The topics covered by the interview guides were disease priorities and priority health issues, perceptions and health seeking behaviour. Both FGDs and IDIs were assisted by an interpreter who translated the conversation from Arabic to French, allowing the study team to take notes. Digital recordings of the FGDs and IDI were transcribed and translated into French, integrating the notes taken during the FGDs or IDIs.

\section{Malacological survey}

At both settlements, individual community members and school-aged children were asked to guide the team to all frequented human-water contact sites. At each site, GPS coordinates and the water parameters temperature $\left({ }^{\circ} \mathrm{C}\right)$, $\mathrm{pH}$, conductivity $(\mu \mathrm{s} / \mathrm{cm})$ and dissolved oxygen $(\mathrm{mg} / \mathrm{L})$ were recorded, using a portable multimeter $\left(\mathrm{Hach}^{\circledR}\right.$, HQ40D, Loveland, USA). For turbidity, a turbidimeter was used [Formazin Nephelometric Units (FNU); $\mathrm{Hach}^{\circledR}, 2100 \mathrm{P}$ Iso]. The snail sampling was performed adhering to standard protocols. In short, for $15 \mathrm{~min}$, all aquatic snails were collected by one person using a scoop or forceps to detach them from aquatic and subaquatic plants [25]. Subsequently, the snails were placed on wet cotton in petri dishes, and transferred to the field laboratory. Snails were identified to the genus or, if possible to species level on site. At midday, each collected snail identified as intermediate host species was placed in a well plate filled with bottled drinking water and exposed to daylight for three hours to induce cercarial shedding [26]. The snail size (in $\mathrm{mm}$ ) and weight (in $\mathrm{mg}$ ) was measured using a calibre and balance, respectively. Thereafter, all snail specimens were conserved in $70 \%$ ethanol, and shipped to the National History Museum, London (NHM) for molecular analysis.

\section{Snail species confirmation using molecular methods}

The snail samples selected for the molecular analyses represented individuals from each collection site. On arrival at the NHM, the snail species identification was confirmed based on morphological characters and samples re-spirited (absolute ethanol) for incorporation into the Schistosomiasis Collection at the Natural History Museum (SCAN) [27]. Photographic images were taken of the snail shells prior to DNA extraction. Specimens were placed in TE buffer $(10 \mathrm{mmol} / \mathrm{L}$ Tris, $0.1 \mathrm{mmol} / \mathrm{L}$ EDTA) $\mathrm{pH} 7.4$ for one hour in order to remove any 
remaining ethanol from within the tissue, which might interfere with subsequent extraction steps [28]. Total genomic DNA was isolated from head/foot tissue using the DNeasy Blood and Tissue kit (Qiagen, UK) according to manufacturer's instructions. DNA was eluted into $200 \mu \mathrm{l}$ sterile water.

\section{Amplification of Cox 1 fragments of snail DNA}

A polymerase chain reaction (PCR) amplification of a partial cytochrome oxidase 1 (Coxl) sequence was performed using primers LCO1490 (5'-GGTCAACAAATC ATAAAG ATATTGG-3' forward) and HCO2198 (5'TAAACTTCAGGGTGACCAAAAAATCA- $3^{\prime}$ reverse) [29]. PCR investigations and sequencing conditions were chosen as previously outlined $[28,30]$.

\section{Checking of sequence data}

The electropherograms produced were checked and Cox 1 sequences edited using Geneious, version 11.0.5 (http:// www.geneious.com) [31]. Sequences were compared to database entries by performing BLAST searches via the National Center for Biotechnology Information against GenBank and EMBL sequence databases; and aligned with reference material.

\section{Sequencing of Schistosoma spp. eggs in urine}

Positive urine samples from Ouinanga Kebir were combined into seven different pools of 8-12 ml respectively one pooled sample of $12 \mathrm{ml}$ for the villages of Ouinanga Serir. Samples were shipped to the diagnostic centre of the Swiss Tropical and Public Health Institute (Swiss TPH) in Basel, Switzerland for further processing. There, each pool was centrifuged at $3000 \times g$ for $10 \mathrm{~min}$. Exactly $500 \mu \mathrm{l}$ of the pellet was re-suspended and transferred to a $2 \mathrm{ml}$ tube containing garnet beads. After addition of $1 \mathrm{ml}$ PBS, the sample was centrifuged $1 \mathrm{~min}$ at $13,000 \times g$ and the supernatant was discarded. The pellet with the garnet beads was frozen 30 min at $-80{ }^{\circ} \mathrm{C}$ and further processed as described by Barda and colleagues [32, 33]. Samples were first tested by simplex generic Schistosoma spp. $28 \mathrm{~S}$ real-time PCR amplifying S. mansoni, S. haematobium, S. intercalatum, S. bovis [34] and additionally $S$. japonicum because of modifications added to the second reverse primer of the assay (Additional file 1: Table S1). The reaction mix contained $1 \times$ TaqMan GenExpression MasterMix (ThermoFisher Scientific, Basel, Switzerland), $800 \mathrm{nmol}$ of forward primer, $400 \mathrm{nmol}$ of each reverse primer and $200 \mathrm{nmol}$ of probe. The samples were subsequently tested by a duplex real-time PCR for the presence of a specific $S$. mansoni TRE region and of $S$. haematobium dra1 sequence [34, 35]. Each reaction mix contained $1 \times$ TaqMan GenExpression MasterMix (ThermoFisher Scientific, Basel, Switzerland), $800 \mathrm{nmol}$ of each primer, $200 \mathrm{nmol}$ each probe (Additional file 1: Table S1).
The thermoprofile of all assays on the QuantStudio5 (ThermoFisher) consisted of $2 \mathrm{~min}$ at $50{ }^{\circ} \mathrm{C}, 10 \mathrm{~min}$ at $95^{\circ} \mathrm{C}$ followed by 45 cycles of $15 \mathrm{~s}$ at $95^{\circ} \mathrm{C}$ and $1 \mathrm{~min}$ at $58^{\circ} \mathrm{C}$. The specificity of all assays was previously tested on a variety of DNA from stool and blood samples including: Ascaris lumbricoides, Blastocystis hominis, Cryptosporidium spp., Dientamoeba fragilis, Encephalitozoon spp., Endolimax nana, Entamoeba coli, E. dispar, E. histolytica, E. moshkovskii, E. polecki, Enterocytozoon bieneusi, Giardia lamblia, Hymenolepis nana, Iodamoeba bütschlii, Sarcocystis spp., Taenia spp., Strongyloides stercoralis, Trichuris trichiura, Plasmodium falciparum, $P$. vivax, $P$. malariae, $P$. ovale, Trypanosoma cruzi, T. brucei, Leishmania spp. and was found to be $100 \%$ specific. Analytical limit of detection (LOD) was tested by a plasmid dilution row ranging from $10^{7}$ to $10^{-1}$ plasmids/ $\mu \mathrm{l}$ containing an insert with the sequence of the Schistosoma real-time PCR product, and was found to be at 10 plasmids $/ \mu$ for all assays. On each real-time PCR plate and for each target we included negative and positive lowcopy plasmid controls.

Subsequently, all samples were tested by classic PCR of the COX gene of S. haematobium and S. bovis as modified from Boon and co-workers (Additional file 1: Table S1) [36]. The reaction mix contained $1 \times$ HotStarTaq Plus Master Mix (Qiagen, Hilden, Germany), $800 \mathrm{nmol}$ of each primer, $5 \mu \mathrm{DNA}$ in a total reaction volume of $50 \mu \mathrm{l}$. The thermoprofile consisted of $5 \mathrm{~min}$ at $94{ }^{\circ} \mathrm{C}$ followed by 40 cycles of $40 \mathrm{~s}$ at $94{ }^{\circ} \mathrm{C}, 40 \mathrm{~s}$ at $58^{\circ} \mathrm{C}$ and $1 \mathrm{~min}$ at $72{ }^{\circ} \mathrm{C}$ and a final step of $10 \mathrm{~min}$ at $72{ }^{\circ} \mathrm{C}$. After visualization on a $2 \%$ agarose-gel, the positive sample of the S. bovis-COX PCR was sent for Sanger sequencing with the primers of amplification at Microsynth AG (Baldach, Switzerland). The sequence was then compared to database entries by performing BLAST searches via the National Center for Biotechnology Information. The sequence is accessible in GenBank under the number: MW937895. A table listing primers and probes is accessible in the supplementary information (Additional file 1: Table S1).

\section{Statistical analysis}

Descriptive statistics of parasitological and malacological data was performed using STATA version 16.0 (STATA Corp Inc., TX, USA) and ArcGIS (Version 10.7.1.; ESRI Inc. ArcMap $^{\text {TM }}$ 10.7, Redlands, CA, USA). Qualitative data analysis included the full review of all transcripts, followed by a descriptive and explorative thematic analysis.

\section{Results}

\section{Parasitological survey}

In both study sites, urinary schistosomiasis was highly prevalent. Indeed, $35.3 \%$ (95\% CI 29.1-41.9\%) of the 
tested participants were $S$. haematobium egg positive in Ounianga Kebir and 54.9\% (95\% CI 40.8-68.2\%) in Ounianga Serir, resulting in an overall prevalence of 39.2\% (95\% CI 33.5-45.1\%) (Table 1). The S. haematobium prevalence was highest among children and adolescents below 18 years of age in both villages. In Ounianga Kebir, more boys than girls were infected (51.1\% versus $36.9 \%)$, whereas in Ounianga Serir girls had a higher prevalence $(72.7 \%)$.

Mapping of the schistosomiasis prevalence by place of living (neighbourhood) shows a slightly higher prevalence for those neighbourhoods closer to a water site where the aquatic intermediate host snail Bulinus truncates was present (Fig. 2, Ounianga Kebir: Yiggybeshi, Ounianga Serir: Roy). Regarding the POC-CCA testing for S. mansoni, $8.6 \%$ of the urine samples showed a positive test results.

More than half of all infected participants harboured a heavy S. haematobium infection $(51.0 \%$; heavy infection: $>50$ eggs $/ 10 \mathrm{ml}$ urine) and the burden was higher in children, whereof over two third were heavily infected (Table 1) [37]. Overall, $10.2 \%$ of all egg-negative, $69.4 \%$ of all light and $92.3 \%$ of all heavily infected participants had severe haematuria, with no big differences between age groups and gender (Fig. 3).

\section{Qualitative survey}

During FGDs in both study sites, abdominal issues and blood in urine were the most frequently mentioned health problems among adults and also in children. Health staff mentioned that the majority of patients seeking care at the centre for any cause additionally suffers from abdominal issues. Among children, diarrhoeal diseases, respiratory infections and scorpion stings were reported as major health issues. Adults also suffered from eye problems, headache and joint pain. Fertility issues are another major concern and women reported difficulties getting pregnant again after they had their second or third child.

A major constraint for people in both sites is the difficult access to health facilities. Accessible facilities are usually underequipped; rarely have drugs available and the personnel had only basic training. To obtain appropriate care and treatment, people needed to travel long distances within Chad (to Faya, Abeche and Ndjamena) or abroad to Libya or Sudan.

Another common theme was the lack of safe drinking water as pumps are rare and open wells are commonly used as water sources. Perceived water quality is low due to salty taste and visible contamination.

The population was well aware of parasitic diseases, yet had limited knowledge on risk factors and transmission. Blood in urine was linked to parasitic infections, low quality of drinking water, water contact at the nearby lakes, or kidney issues. Kadi and Kouli are two local names for parasite infections linked to abdominal pain. Kadi describes an intestinal worm infection causing symptoms like intestinal spasms and flatulence, increased appetite with the tendency of weight loss. As a traditional treatment, infected people are given natron, a naturally occurring form of sodium bicarbonate, or an extract of the roots of a plant called Boa to initiate diarrhoea,

Table 1 Prevalence of S. haematobium infection by egg positivity and infection intensities, haematuria and S. mansoni test results from POC-CCA testing (trace results excluded) in the study population from Ounianga Serir and Ounianga Kebir, Chad, 2019

\begin{tabular}{|c|c|c|c|c|c|}
\hline & \multicolumn{2}{|c|}{ Ounianga Kebir $(n=207)$} & \multicolumn{2}{|c|}{ Ounianga Serir $(n=51)$} & \multirow[t]{2}{*}{ Total $n(\%, 95 \% C l)$} \\
\hline & Male $n(\%, 95 \% C l)$ & Female $n(\%, 95 \% C l)$ & Male $n(\%, 95 \% C l)$ & Female $n(\%, 95 \% C l)$ & \\
\hline Total number of participants & 65 & 142 & 21 & 30 & 258 \\
\hline Participants aged $<18$ years & $47(72)$ & $65(46)$ & $14(67)$ & $11(37)$ & $137(53)$ \\
\hline \multicolumn{6}{|c|}{ S. haematobium infection (egg positive) } \\
\hline Total no. positive & $27(41.5,30.0-54.0)$ & $46(32.4,25.2-40.5)$ & $11(52.4,30.2-73.6)$ & $17(56.7,37.9-73.7)$ & $101(39.2,33.5-45.1)$ \\
\hline Positives $<18$ years* & $24(51.1,36.6-65.3)$ & $24(36.9,25.9-49.5)$ & $9(64.3,34.1-86.3)$ & $8(72.7,35.4-92.8)$ & $65(47.5,39.2-55.8)$ \\
\hline \multicolumn{6}{|c|}{ S. haematobium heavy infection ( $\geq 50$ eggs/10 $\mathrm{ml}$ urine) } \\
\hline Total no. heavy infection & $13(50.0,30.5-69.5)$ & $21(45.7,31.6-60.5)$ & $8(72.7,35.4-92.8)$ & $9(52.9,28.1-76.4)$ & $51(51.0,41.2-60.7)$ \\
\hline Heavy infection $<18$ years & $13(56.5,34.8-76.0)$ & $14(58.3,36.9-77.0)$ & $8(88.9,37.5-99.1)$ & $7(87.5,32.0-99.1)$ & $42(65.6,53.0-76.4)$ \\
\hline \multicolumn{6}{|l|}{ Haematuria } \\
\hline Total no. positive & $36(55.4,43.0-67.2)$ & $82(57.8,49.5-65.6)$ & $12(57.1,34.2-77.4)$ & $22(73.3,53.9-86.6)$ & $152(58.9,52.9-64.6)$ \\
\hline Positives $<18$ years* & $26(55.3,40.6-69.2)$ & $39(60.0,47.5-71.3)$ & $9(64.3,34.1-86.3)$ & $9(81.8,42.1-96.5)$ & $83(60.6,52.2-68.4)$ \\
\hline \multicolumn{6}{|c|}{ S. mansoni infection (from POC-CCA test results) } \\
\hline Total no. positive & $3(4.7,1.5-13.8)$ & $11(8.4,4.7-14.5)$ & $5(23.8,9.5-48.2)$ & $2(7.1,1.6-26.2)$ & $21(8.6,5.7-12.8)$ \\
\hline Positives $<18$ years* & $3(6.5,2.0-19.0)$ & $5(8.3,3.4-18.8)$ & $5(35.7,13.7-65.9)$ & $1(9.1,0.9-53.6)$ & $14(10.7,6.4-17.2)$ \\
\hline
\end{tabular}

*(\%) from all participants $<18$ years of age; POC-CCA: Point-of-care circulating cathodic antigen 


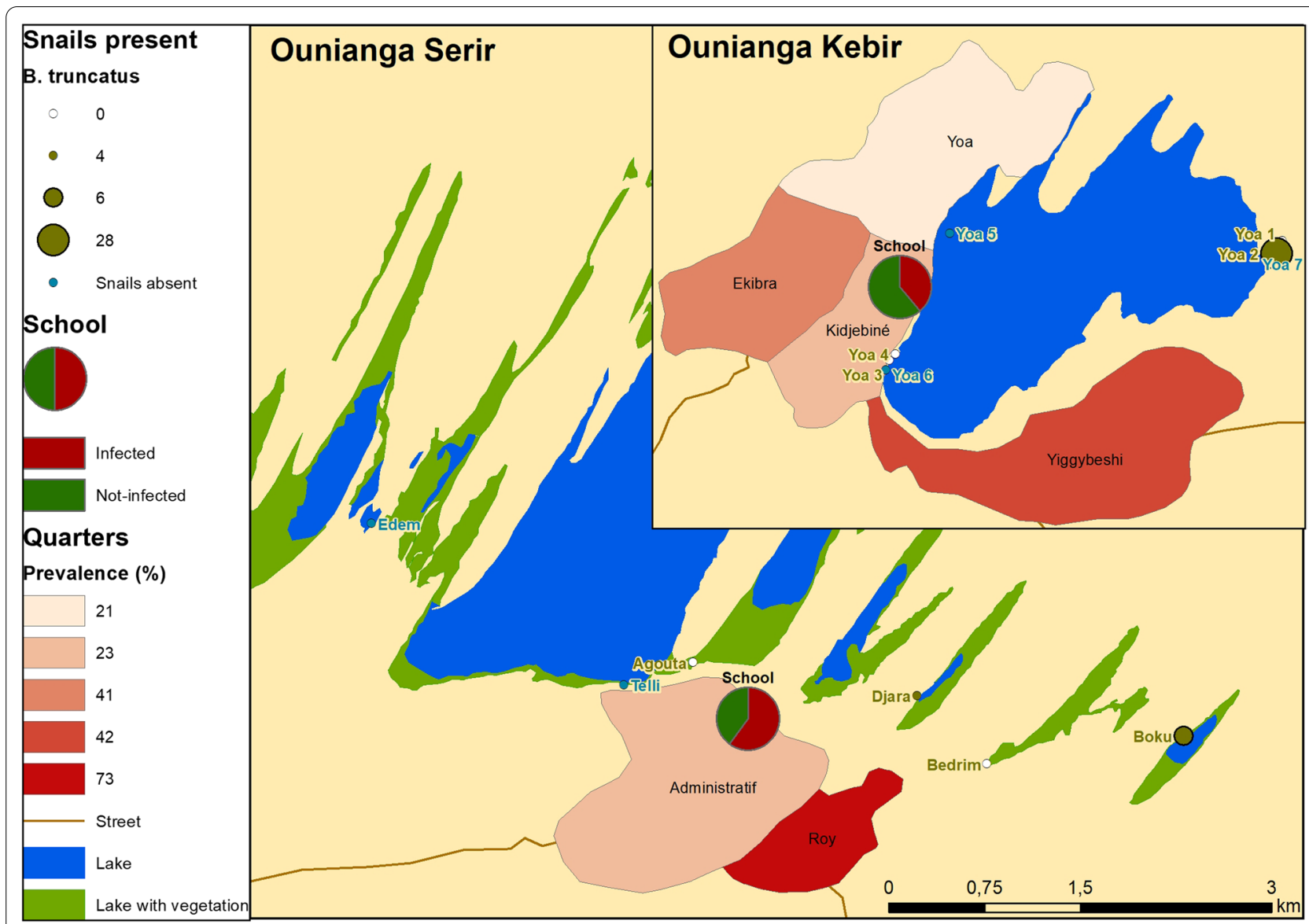

Fig. 2 Map showing the urinary schistosomiasis prevalence and snail abundance for Ounianga Kebir and Serir. The prevalence of urinary schistosomiasis among participants is stratified by neighbourhood. For each water site sampled, the abundance of the intermediate host snail Bulinus truncatus is indicated

causing a worm with a red 'mouth' to leave the body via the excrements. The symptoms described for Kouli correlate with symptoms of the parasite Enterobius vermicularis such as persistent itching in the perianal area and sleep disturbances. The traditional treatment administered to Kouli patients are eating butter or drinking an extract of a medical plant called Chi.

Ouco is the local term to describe the health condition related to blood in urine combined with pain while urinating and reduced male erectile function. In traditional medicine, the urine of the animal called Nii (Fennec Fox, Vulpes zerda) is believed to have a curative effect.

The reported level of satisfaction with access to medical treatment for the above mentioned health issues is mixed. Important challenges mentioned included stock outs of medicines, lack of diagnostic means and noneffectiveness of the medical treatment received. Especially the female FGD participants expressed a need for health education and sensitization among the population.

\section{Malacological survey}

Among a total of 17 different collection sites, 8 harboured freshwater snails (Table 2, Fig. 2). The highest numbers of snails were collected from the two intermediate host snail species Radix natalensis $(n=42)$ and Bulinus truncatus $(n=38)$, and four species of no medical importance $(n=42)$. Snails were identified using shell shape and a partial COX1 sequence. Particularly high numbers of any snail species were collected at two sites, namely Yoa 2 $(n=35)$ in Ounianga Kebir and Agouta $(n=34)$ in Ounianga Kebir. Among all snails, only one B. truncatus was shedding cercariae (from Yoa 2). Upon testing, they were recognized to not represent $S$. haematobium cercariae, and consequently were not further studied. The average shell height of all $R$. natalensis specimen was $10.6 \mathrm{~mm}$ (95\% CI: 9.08-12.11 mm), and $6.66 \mathrm{~mm}$ (95\% CI: $5.97-$ $7.34 \mathrm{~mm}$ ) for B. truncatus,

Across all sites where snails were found, the average water temperatures was $18.9^{\circ} \mathrm{C}$ (standard deviation \pm 3.3 ), the average oxygen content was $4.8 \mathrm{mg} / \mathrm{L}( \pm 2.1)$ and a 


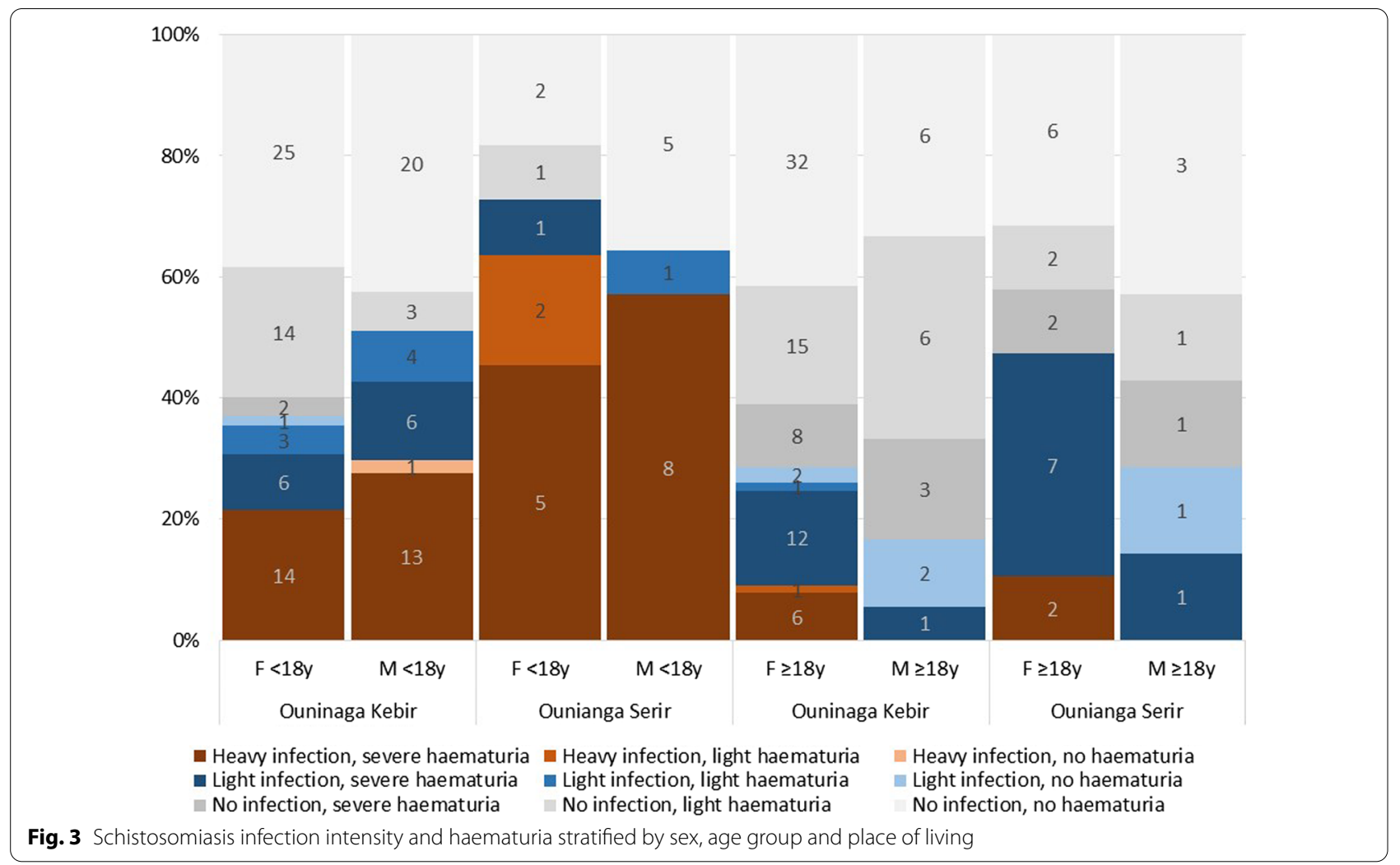

turbidity of 3.0 FNU $( \pm 1.4)$. The sites without snails were characterized by a wide range of measured water parameters, i.e., temperature of $22.1{ }^{\circ} \mathrm{C}$ (range 14.1-28.2), oxygen $5.9 \mathrm{mg} / \mathrm{L}$ (range 1.1-15.0) and turbidity 267.0 FNU (range: $1.0->1000.0$ ). Snails obviously preferred the $\mathrm{pH}$ range between 7.0 and 8.8 compared the sites without snails with a $\mathrm{pH}$ varying between 7.0 and 10.5. Inconclusive results were found for the conductivity comparing sites with and without snails with a range of $6.0-1941.0 \mu \mathrm{s} / \mathrm{cm}$ and 2.8 to $>2500.0 \mu \mathrm{s} / \mathrm{cm}$, respectively (Table 2 ).

\section{Sequencing of Schistosoma spp. eggs in urine}

All eight urine pools were positive in the generic Schistosoma spp. $28 \mathrm{~S}$ real-time assay, in the S. haematobium dra1 real-time assay and in the S. haematobium COX1 PCR consistent with the presence of $S$. haematobium eggs in all pools. No pool was positive for S. mansoni TRE real-time PCR. One pool from the village of Ouinanga Serir was positive for S. bovis COX1. This result indicates the possibility of the presence of $S$. haematobium X bovis hybrids as observed in previous studies in West Africa [36, 38].

\section{Discussion}

According to the statements of the local authorities, this exploratory study was the very first time a medical research team visited the district of Ounianga, Ennedi
Ouest province in Chad. Our research revealed a high prevalence of $S$. haematobium in the population of both Ounianga Kebir and Serir villages. Living specimens of $B$. truncatus were found at both sites, whereas the previous findings were fossils dating back to the early Holocene [17]. These findings strongly suggest ongoing local schistosome transmission in this desert oasis environment.

The larger of the two villages, Ounianga Kebir, had an overall lower schistosomiasis prevalence compared to the smaller village of Ounianga Serir (35.3\% versus 54.9\%). In the different neighbourhoods of Ounianga Kebir the prevalence varied and ranged from 21 to $42 \%$ (Fig. 2). This may be partly explained by the proximity to the rare freshwater sites that are used for washing cloth, bathing and swimming. For example, Lake Yoa with its cold temperature and high salinity is fed by numerous freshwater springs. These provide habitats for the intermediate host snails, and the neighbourhood with the highest prevalence was the one closest to a freshwater spring. The quarters with lower prevalence were closer to freshwater sources including the two hot springs (Yoa 5 and 6). Here, the high water temperature might explain the absence of snails [39]. The two adjacent sampling sites Yoa 3 and 4 are cold and only used for irrigating the surrounding gardens or for watering livestock. Interestingly, at these two sites snails of the species Radix natalesis were found, the 
Table 2 Snail abundance and water parameters for each sampling site

\begin{tabular}{|c|c|c|c|c|c|c|c|c|}
\hline \multicolumn{2}{|l|}{ Site* } & Snail species & $\begin{array}{l}\text { No. of snails } \\
\text { found }\end{array}$ & $\begin{array}{l}\text { Temperature } \\
\left({ }^{\circ} \mathrm{C}\right)\end{array}$ & $\begin{array}{l}\text { Conductivity } \\
(\mu \mathrm{s} / \mathrm{cm})\end{array}$ & $\mathrm{pH}$ & Oxygen (mg/L) & Turbidity (FNU) \\
\hline \multicolumn{9}{|c|}{ Sampling sites where snails were present } \\
\hline \multicolumn{9}{|l|}{ Ounianga Kebir } \\
\hline \multirow[t]{3}{*}{ Yoa (Girki) } & $1^{*}$ & $\begin{array}{l}\text { No host snail spe- } \\
\text { cies }\end{array}$ & 0 & 17.5 & 1054.0 & 6.8 & 2.7 & 1.3 \\
\hline & $2^{*}$ & B. truncatus & 28 & 14.5 & 1046.0 & 6.9 & 4.1 & 2.5 \\
\hline & & R. natalensis & 6 & & & & & \\
\hline \multirow[t]{2}{*}{ Yoa (source 2) } & $3^{*}$ & R. natalensis & 19 & 22.7 & 1941.0 & 7.1 & 3.2 & 1.9 \\
\hline & $4^{*}$ & R. natalensis & 7 & 22.8 & 2.56 & 7.0 & 3.0 & 3.7 \\
\hline \multicolumn{9}{|l|}{ Ounianga Serir } \\
\hline \multicolumn{2}{|l|}{ Agouta } & R. natalensis & 7 & 14.5 & 8.0 & 8.3 & 4.9 & 3.5 \\
\hline \multicolumn{2}{|l|}{ Djara } & B. truncatus & 4 & 19.7 & 6.0 & 8.5 & 6.6 & 2.4 \\
\hline \multirow{2}{*}{\multicolumn{2}{|c|}{ Boku }} & B. truncatus & 6 & 20.8 & 1524.0 & 8.8 & 8.8 & 5.9 \\
\hline & & R. natalensis & 3 & & & & & \\
\hline \multicolumn{2}{|l|}{ Bedrim } & $\begin{array}{l}\text { No host snails spe- } \\
\text { cies }\end{array}$ & 0 & 18.7 & 7.3 & 8.4 & 5.2 & 3.0 \\
\hline \multicolumn{9}{|c|}{ Sampling sites where no snails were present } \\
\hline \multicolumn{9}{|l|}{ Ounianga Kebir } \\
\hline \multicolumn{3}{|c|}{ Yoa 5 (hot source) } & & 28.4 & 2.8 & 7.0 & 2.9 & 4.9 \\
\hline \multicolumn{3}{|c|}{ Yoa 6 (hot source) } & & 27.7 & 2107.0 & 7.4 & 3.2 & 16.3 \\
\hline \multicolumn{3}{|l|}{ Yoa 7 (lake) } & & 14.4 & 290.0 & 10.3 & 1.1 & 158.0 \\
\hline \multicolumn{3}{|l|}{ Uma red } & & 27.5 & $>2000.0$ & 10.1 & 14.2 & 85.8 \\
\hline \multicolumn{3}{|l|}{ Uma blue } & & 18.6 & $>2000.0$ & 10.5 & 15.0 & 118.0 \\
\hline \multicolumn{3}{|c|}{ Uma (hot spring) } & & 28.2 & 4.0 & 9.1 & 3.6 & 14.9 \\
\hline \multicolumn{3}{|l|}{ Forodone } & & 19.1 & 31.1 & 9.8 & 2.0 & $>1000.0$ \\
\hline \multicolumn{9}{|l|}{ Ounianga Serir } \\
\hline \multicolumn{3}{|l|}{ Telli } & & 21.3 & 13.7 & 10.7 & 2.7 & 4.5 \\
\hline \multicolumn{2}{|l|}{ Edem } & & & 14.1 & 3.5 & 8.7 & 8.3 & 1.0 \\
\hline
\end{tabular}

*All sampling sites are shown in Fig. 2

intermediate host of the liver fluke Fasciola spp. In Ounianga Serir, there are no hot springs and the two freshwater lakes (Djara and Boku) are used for all water-related activities. In both, B. truncatus were present and the lakes' close proximity to the quarter Roy may explain the high urinary schistosomiasis prevalence. The snails were identified using shell morphology and molecular methods; diversity within species was low, however it would be of interest to sequence further with other genes such as ITS. A single snail was found to be shedding cercariae but not S. haematobium. To inform on where transmission could be occurring, additional testing of the snails for prepatent infections will be carried out.

About half of the adult participants and two thirds of the children with a positive parasitological test suffered from heavy S. haematobium infections. Our data show that the infection intensity is associated with the severity of haematuria, pointing towards chronic schistosomiasis caused by long-term exposure and recurrent reinfection. Hence, the major health problems reported by the local population, namely abdominal issues and blood in urine, may well be due to schistosomiasis, and are likely the consequences of the lacking access to diagnostic and treatment options, and the absence of any preventive intervention. Similar observations have also been reported from other remote areas in Chad [40].

The study was designed as an exploratory study with the aim to reveal the presence of the full Schistosoma spp. lifecycle in these desert lakes. Its scope was therefore limited and findings leave several factors unaddressed at this stage. For example, the men's main activities involve working in natron extraction sites, trading using traditional caravans, and raising livestock through mobile pastoralism. Hence, during the visit of the study team, the majority of men aged 16-60 years were absent, resulting in an over-representation of women in the study population (ratio 1:2). Regarding the S. mansoni diagnostics that showed a positive POC-CCA result for $8.6 \%$ of all urine 
samples, we cannot conclude with certainty that $S$. mansoni is present in the study population as no stool samples were collected and hence, no parasitological proof of $S$. mansoni infection is available. Of note, according to the test handbook, also a heavy infection with $S$. haematobium can lead to a positive test result [24]. It is also significant that no intermediate host snails of the genus Biomphalaria were found. However, the exploratory study was conducted in January while snail abundance is highly seasonal [26].

\section{Conclusions}

This exploratory study presents the first modern evidence of urinary schistosomiasis among the population of these oasis villages. A high prevalence of about $40 \%$ of urinary schistomiasis was found, with no access to diagnostics and effective treatment with praziquantel. The presence of intermediate host snails in this isolated area suggests ongoing local transmission. There is clearly a need for further studies to fully understand the current epidemiological situation. However, apart from further studies the main problems are already evident; namely the lack of health education, diagnostics and access to treatment. With a combined approach, including sensitization, mass drug administration, and morbidity management the control or even elimination of urinary schistosomiasis in this population might be possible.

\section{Abbreviations}

BASEC: Business Administration System for Ethics Committees; CDC: Centre for Disease Control; Cl: Confidence interval; CNBT: Comité National de Bioéthique du Tchad; EPI: Expanded Programme on Immunization; FGD: Focus group discussion; FNU: Formazin nephelometric units; IDI: In-depth interview; LOD: Analytical limit of detection; NHM: Natural History Museum; NTD: Neglected tropical disease; POC-CCA: Point-of-care circulating cathodic antigen; SCAN: Schistosomiasis Collection at the Natural History Museum; UNESCO: United Nations Educational, Scientific and Cultural Organisation; WHO: World Health Organization.

\section{Supplementary Information}

The online version contains supplementary material available at https://doi. org/10.1186/s40249-021-00930-4.

Additional file 1. List of primers and probes used for sequencing of Schistosoma spp. eggs.

\section{Acknowledgements}

We are deeply grateful to Dr. Baba Mallaye, director of the Centre d'Appui à la Recherche (CNAR), Ndjamena, Chad, who not only guided us through the desert to safely arrive at the Lakes of Ounianga, but also introduced us and the purpose of our research visit to the local authorities. We thank the population of Ounianga Kebir and Ounianga Serir for hosting us and for their willingness to participate in the study. Special thanks go to the staff of the health centers at the study sites for their support. Without the tireless engagement of our study nurse Ali Abba Abakar, this work would not have succeeded. Nomadic pastoralists at Lake Chad have triggered this study, and we like to express here our deepest thanks for their hospitality and sharing of their wisdom.

\section{Authors' contributions}

$\mathrm{HG}$ conceived and designed the study protocol with input from PS; $A A B, H G$, $\mathrm{RO}$ and WM implemented the research in Chad; $A A B, H G, M A, R O$ and WM carried out the field work and the parasitological examinations, together with a medical team; HG and WM sampled the snails, and FA and RC performed the genetic sequencing and analysis for species confirmation. RW and SP performed the genetic sequencing and analysis of the Schistosoma samples. AAB, FA, HG, RO and WM analysed and interpreted the epidemiological data; HG, $\mathrm{RO}$ and WM drafted the manuscript; all authors critically revised the manuscript for intellectual content and approved the final manuscript. HG is the guarantor of the paper. All authors read and approved the final manuscript.

\section{Funding}

This work has received funding through a starting grant from the Rudolf Geigy Foundation (Basel, Switzerland).

\section{Availability of data and materials}

Data will be available on request by email to the corresponding author.

\section{Declarations}

\section{Ethics approval and consent to participate}

The study received approval from the ethics committee Northwest and Central Switzerland (reference no. BASEC Nr Req-2018-0120) and the 'Comité National de Bioéthique du Tchad' (CNBT) in N'Djamena, Chad (reference no. 134/PR/MESRI/SG/CNBT/2018). Research authorization was granted by the Chadian Ministry of Health and its 'Direction de la Lutte contre la Maladie et de la Promotion de la Santé' (reference no. 007/PR/MSP/DG/DLMPS/2018). Upon arrival in the study villages, an assembly was organized with the community representatives to discuss the study objectives and procedures. The traditional leaders, together with the local authorities, discussed the study and decided about concrete participation. Once a collective decision had been reached, written informed consent was obtained from the community representatives. In line with high illiteracy rates among the general population, individual participants consented orally. These consent procedures had received approval by the respective ethics committees. Those participants with a positive test result from either filtration or POC-CCA testing were invited to the health centre/health post and were administered praziquantel in the adequate dose ( $40 \mathrm{mg} / \mathrm{kg}$ ) by the study nurse.

\section{Consent for publication}

All authors approved submission for publication of this manuscript.

\section{Competing interests}

The authors declare that they have no competing interests.

\section{Author details}

${ }^{1}$ Swiss Tropical and Public Health Institute, Basel, Switzerland. ${ }^{2}$ University of Basel, Basel, Switzerland. ${ }^{3}$ Institut de Recherche en Elevage Pour le Développement, Ndjamena, Chad. ${ }^{4}$ Geology Department, University of Ndjamena, Ndjamena, Chad. ${ }^{5}$ Department of Life Sciences, Natural History Museum, London, UK.

Received: 25 October 2021 Accepted: 21 December 2021

Published online: 07 January 2022

\section{References}

1. WHO. Ending the neglect to attain the sustainable development goals. A road map for neglected tropical diseases 2021-2030. Geneva: World Health Organization; 2020.

2. Ehrenberg N, Ehrenberg JP, Fontes G, Gyapong M, Rocha EMM, Steinmann P, et al. Neglected tropical diseases as a barometer for progress in health systems in times of COVID-19. BMJ Glob Health. 2021;6(4):e004709.

3. Colley DG, Bustinduy AL, Secor WE, King CH. Human schistosomiasis. Lancet. 2014;383(9936):2253-64.

4. Verjee MA. Schistosomiasis: still a cause of significant morbidity and mortality. Res Rep Trop Med. 2019;10:153-63. 
5. King CH. Parasites and poverty: the case of schistosomiasis. Acta Trop. 2010;113(2):95-104

6. Vale N, Gouveia MJ, Rinaldi G, Brindley PJ, Gartner F, Correia da Costa JM. Praziquantel for schistosomiasis: single-drug metabolism revisited, mode of action, and resistance. Antimicrob Agents Chemother 2017;61(5):e02582-e2616.

7. Monjour L, Niel G, Mogahed A, Sidat M, Gentilini M. Contribution a l'étude de l'épidemiologie de la bilharziose dans les régions saheliennes et sahariennes de Mauritanie (evaluation sero-immunologique. Année 1973). Bull Soc Pathol Exot. 1983;76(2):157-65.

8. Chippaux JP, Boulanger D, Bremond P, Campagne G, Vera C, Sellin B. The WHO collaborating centre for research and control of schistosomiasis at Niamey, Niger. Mem Inst Oswaldo Cruz. 1997;92(5):725-8.

9. Medina DC, Findley SE, Doumbia S. State-space forecasting of Schistosoma haematobium time-series in Niono, Mali. PLoS Negl Trop Dis. 2008;2(8):e276

10. Cha S, Elhag MS, Lee Y-H, Cho D-S, Ismail HA, Hong S-T. Epidemiological findings and policy implications from the nationwide schistosomiasis and intestinal helminthiasis survey in Sudan. Parasit Vectors. 2019;12(1):429.

11. Greter H, Batil AA, Ngandolo BN, Alfaroukh IO, Moto DD, Hattendorf $J$, et al. Human and livestock trematode infections in a mobile pastoralist setting at Lake Chad: added value of a One Health approach beyond zoonotic diseases research. Trans R Soc Trop Med Hyg. 2017:111(6):278-84.

12. Moreau JP, Boudin C, Trotobas J, Roux J. Répartition des schistosomiases dans les pays francophones d'Afrique de l'ouest. Med Trop. 1980;40(1):23-30

13. Buck AA, Anderson RI, Sasaki TT, Kawata K. Health and disease in Chad. Epidemiology, culture, and environment in five villages. Baltimore and London: The Johns Hopkins Press; 1970.

14. Ranque J, Rioux JA. Urinary schistosomiasis in the oasis of Faya-Largeau. North Chad Med Afr Noire. 1963;10(6):287-90.

15. Boelee $\mathrm{E}$, Laamrani $\mathrm{H}$. Environmental control of schistosomiasis through community participation in a Moroccan oasis. Trop Med Int Health. 2004;9(9):997-1004

16. el-Sayed HF, Rizkalla NH, Mehanna S, Abaza SM, Winch PJ. Prevalence and epidemiology of Schistosoma mansoni and S. haematobium infection in two areas of Egypt recently reclaimed from the desert. Am J Trop Med. 1995;52(2):194-8.

17. Van Bocxlaer B, Verschuren D, Schettler G, Kröpelin S. Modern and early Holocene mollusc fauna of the Ounianga lakes (northern Chad): implications for the palaeohydrology of the central Sahara. J Quaternary Sci. 2011;26(4):433-47.

18. Creutz M, Van Bocxlaer B, Abderamane M, Verschuren D. Recent environmental history of the desert oasis lakes at Ounianga Serir. Chad J Paleolimnol. 2016;55(2):167-83.

19. Deuxième Recencement General de la Population et de l'Habitat. Institut National de la Statistique. N'Djamena, Chad: Ministère de l'économie et du plan; 2009

20. Milligan P, Njie A, Bennett S. Comparison of two cluster sampling methods for health surveys in developing countries. Int J Epidemiol. 2004;33(3):469-76.

21. Doehring E, Feldmeier $H$, Daffalla AA. Day-to-day variation and circadian rhythm of egg excretion in urinary schistosomiasis in the Sudan. Ann Trop Med Parasitol. 1983;77(6):587-94.

22. WHO. Prevention and control of schistosomiasis and soil-transmitted helminthiasis. Report of a WHO expert committee. Geneva: World Health Organization; 2002. Report No.: 0512-3054 (Print) 0512-3054 (Linking).

23. van Dam GJ, Wichers JH, Ferreira TM, Ghati D, van Amerongen A, Deelder AM. Diagnosis of schistosomiasis by reagent strip test for detection of circulating cathodic antigen. J Clin Microbiol. 2004;42(12):5458-61.

24. Greter H, Krauth SJ, Ngandolo BN, Alfaroukh IO, Zinsstag J, Utzinger J. Validation of a point-of-care circulating cathodic antigen urine cassette test for Schistosoma mansoni diagnosis in the Sahel, and potential crossreaction in pregnancy. Am J Trop Med Hyg. 2016;94(2):361-4.

25. Mandahl-Barth G. Key to the identification of east and central African freshwater snails of medical and veterinary importance. Bull World Health Organ. 1962;27:135-50.

26. Moser W, Greter H, Schindler C, Allan F, Ngandolo BN, Moto DD, et al. The spatial and seasonal distribution of Bulinus truncatus, Bulinus forskalii and
Biomphalaria pfeifferi, the intermediate host snails of schistosomiasis, in N'Djamena. Chad Geospat Health. 2014;9(1):109-18.

27. Emery AM, Allan FE, Rabone ME, Rollinson D. Schistosomiasis collection at NHM (SCAN). Parasit Vectors. 2012;5:185

28. Kane RA, Stothard JR, Emery AM, Rollinson D. Molecular characterization of freshwater snails in the genus Bulinus: a role for barcodes? Parasit Vectors. 2008; 1 (1).

29. Folmer O, Black M, Hoeh W, Lutz R, Vrijenhoek R. DNA primers for amplification of mitochondrial cytochrome c oxidase subunit I from diverse metazoan invertebrates. Mol Mar Biol Biotechnol. 1994;3(5):294-9.

30. Allan F, Sousa-Figueiredo JC, Emery AM, Paulo R, Mirante C, Sebastião A, et al. Mapping freshwater snails in north-western Angola: distribution, identity and molecular diversity of medically important taxa. Parasit Vectors. 2017;10(1):460.

31. Kearse M, Moir R, Wilson A, Stones-Havas S, Cheung M, Sturrock S, et al. Geneious Basic: an integrated and extendable desktop software platform for the organization and analysis of sequence data. Bioinformatics. 2012;28(12):1647-9.

32. Barda B, Schindler C, Wampfler R, Ame S, Ali SM, Keiser J. Comparison of real-time PCR and the Kato-Katz method for the diagnosis of soil-transmitted helminthiasis and assessment of cure in a randomized controlled trial. BMC Microbiol. 2020;20(1):298.

33. Cnops L, Tannich E, Polman K, Clerinx J, Van Esbroeck M. Schistosoma realtime PCR as diagnostic tool for international travellers and migrants. Trop Med Int Health. 2012;17(10):1208-16.

34. Cnops L, Soentjens P, Clerinx J, Van Esbroeck M. A Schistosoma haematobium-specific real-time PCR for diagnosis of urogenital schistosomiasis in serum samples of international travelers and migrants. PLoS Negl Trop Dis. 2013;7(8):e2413.

35. Wichmann D, Poppert S, Von Thien H, Clerinx J, Dieckmann S, Jensenius $\mathrm{M}$, et al. Prospective European-wide multicentre study on a blood based real-time PCR for the diagnosis of acute schistosomiasis. BMC Infect Dis. 2013;13(55).

36. Boon NAM, Van Den Broeck F, Faye D, Volckaert FAM, Mboup S, Polman $\mathrm{K}$, et al. Barcoding hybrids: heterogeneous distribution of Schistosoma haematobium $\times$ Schistosoma bovis hybrids across the Senegal River Basin. Parasitology. 2018;145(5):634-45.

37. Utzinger J, Becker SL, van Lieshout L, van Dam GJ, Knopp S. New diagnostic tools in schistosomiasis. Clin Microbiol Infection. 2015;21 (6):529-42.

38. Catalano S, Sène M, Diouf ND, Fall CB, Borlase A, Léger E, et al. Rodents as natural hosts of zoonotic Schistosoma species and hybrids: an epidemiological and evolutionary perspective from West Africa. J Infect Dis. 2018;218(3):429-33

39. Kazibwe F, Makanga B, Rubaire-Akiiki C, Ouma J, Kariuki C, Kabatereine $\mathrm{NB}$, et al. Ecology of Biomphalaria (Gastropoda: Planorbidae) in Lake Albert, Western Uganda: snail distributions, infection with schistosomes and temporal associations with environmental dynamics. Hydrobiologia. 2006;568(1):433-44.

40. Greter $\mathrm{H}$, Cowan N, Ngandolo BN, Kessely H, Alfaroukh IO, Utzinger J, et al. Treatment of human and livestock helminth infections in a mobile pastoralist setting at Lake Chad: attitudes to health and analysis of active pharmaceutical ingredients of locally available anthelminthic drugs. Acta Trop. 2017:175:91-9. 